\title{
DIREITO OU PRIVILÉGIO? DESIGUALDADES DIGITAIS, PANDEMIA E OS DESAFIOS DE UMA ESCOLA PÚBLICA
}

Right or privilege? Digital inequalities, the pandemic, and the challenges of a public school

¿Derecho o privilegio? Desigualdades digitales, pandemia y los desafíos de una escuela pública

RENATA MOURÃO MACEDO ${ }^{I^{*}}$

DOI: https://doi.org/10.1590/S2178-149420210203

\footnotetext{
Universidade de São Paulo - São Paulo (SP), Brasil.

*Renata Mourão Macedo é antropóloga e pós-doutoranda na Faculdade de Educação da Universidade de São Paulo com bolsa Fundação de Amparo à Pesquisa do Estado de São Paulo (Processo no 19/25903-0), processo vinculado ao projeto temático Saberes e Práticas em fronteiras: por uma história transnacional da educação (1810-...) (Processo nº 18/26699-4) (renatagmourao@hotmail.com)

(D) https://orcid.org/0000-0002-2807-4605
}

Artigo recebido em 29 de dezembro de 2020 e aprovado para publicação em 11 de março de 2021. 


\title{
RESUMO
}

0 artigo discute alguns dos impactos na educação durante a pandemia de COVID-19 no Brasil em 2020, focalizando a questão do acesso às atividades online por estudantes do ensino básico. 0 texto está dividido em duas partes: na primeira, debate-se a transferência do ensino presencial para o ensino remoto, tendo como eixo desigualdades digitais, privilégios sociais e direito à educação; na segunda, é analisado o caso da Escola de Aplicação da Faculdade de Educação da Universidade de São Paulo, em São Paulo (SP), com base nas experiências e nos desafios enfrentados na transferência para 0 ensino remoto. 0 artigo aponta para a insuficiência de políticas públicas educacionais no período, que não garantiram a conectividade e o direito à educação no país em meio à crise.

PALAVRAS-CHAVE: Educação; Ensino Remoto; Pandemia; Desigualdades Digitais.

\begin{abstract}
The article discussed some of the impacts on education during the COVID-19 pandemic in Brazil in 2020, focusing on the issue of access to online activities by basic school students. The text is divided into two parts: in the first part, the transfer of face-to-face education to remote education was discussed, focusing on digital inequalities, social privileges, and the right to education; in the second part, the case of the Application School of FEUSP, in São Paulo (SP), was analyzed based on the experiences and challenges faced in the transfer to remote education. The text notes the insufficiency of public educational policies in the period, which did not guarantee connectivity and the right to education in the country in the midst of the crisis.
\end{abstract}

KEYWORDS: Education; Remote Learning; Pandemic; Digital Inequalities.

\section{RESUMEN}

El artículo analiza los impactos en la educación durante la pandemia de COVID-19 en Brasil en 2020, centrándose en el tema del acceso a las actividades online por parte de estudiantes de la educación básica. El texto se divide en dos partes: en la primera, se debate la transferencia de la enseñanza presencial a la educación remota, centrándose en las desigualdades digitales, los privilegios sociales y el derecho a la educación; en la segunda, se analiza el caso de la Escuela de Aplicación FEUSP, en São Paulo (SP), a partir de las experiencias y desafíos enfrentados en la transferencia a la educación remota. El texto apunta a la insuficiencia de las políticas públicas educativas en el período, que no garantizaban la conectividad y el derecho a la educación en el país.

PALABRAS CLAVE: Educación; Enseñanza Remota; Pandemia; Desigualdades Digitales. 


\section{INTRODUÇÃO}

Alguém já escreveu que a internet é um instrumento democrático. Tomada ao pé da letra, essa afirmação é falsa. Eu gostaria de corrigi-la acrescentando: a internet é um instrumento potencialmente democrático. No atual momento, o lema da internet está encapsulado nas palavras politicamente incorretas de Jesus: "a quem tem, mais será dado"

(Mateus 13: 10-12). Em vez de reduzir as distâncias atreladas à hierarquia social, a internet as exacerba. Carlos Ginzburg (2016, s/p, grifo nosso)

$\mathrm{E}^{\mathrm{m}}$ m março de 2020, quando foi anunciado no Brasil o fechamento repentino das escolas pela propagação da pandemia causada pelo coronavírus, o tempo hábil para organização da continuidade do ano letivo foi curto. Em diferentes escolas públicas e privadas, dúvidas não pararam de surgir: as atividades devem esperar o fim da pandemia ou a escola deve adotar o ensino remoto? No caso de adoção de atividades online, quantos estudantes acessam a internet de suas casas? Quantos estudantes possuem equipamentos eletrônicos adequados para 0 ensino a distância? De quais modos o ensino formulado para ser realizado de modo presencial poderá ser migrado para o ambiente online? Em suma: se a educação for transferida para o ambiente online, seguirá como um direito ou será um privilégio? Entre tantas outras perguntas que marcaram esse momento de crise. Seguindo as provocações realizadas pelo historiador Carlos Ginzburg, em 2016, sobre as hierarquias implicadas no acesso à internet, tratava-se de questionar como lidar com um processo histórico de tal gravidade sem exacerbar ainda mais as desigualdades sociais.

Neste artigo, discutem-se alguns dos impactos na educação durante a pandemia de COVID-19 no Brasil em 2020, focalizando a questão do acesso e do acompanhamento das atividades remotas online por estudantes do ensino básico. 0 texto está divido em duas partes: na primeira, debate-se a transferência do ensino presencial para o ensino remoto em meio à pandemia, tendo como eixo desigualdades digitais, privilégios sociais e direito à educação no Brasil. Na segunda parte, analisam-se alguns dos desafios, ações e experiências cotidianas apresentadas pela Escola de Aplicação da Faculdade de Educação da Universidade de São Paulo (EA-FEUSP), escola pública localizada em São Paulo (SP), durante a pandemia de COVID-19 em 2020. Tal processo, ainda em andamento, apontou para a necessidade de reconhecer e enfrentar desigualdades sociais e digitais entre os estudantes, problema que já era muito presente no país, mas que se tornou uma questão central nesse período de crise.

Em paralelo, debate-se a ausência de políticas educacionais focadas em garantir a conectividade e o direito à educação no ano de 2020, ausência que se deu especialmente em nível federal. Deixados à própria sorte, coube às diversas escolas públicas, famílias e 
professores encontrarem soluções criativas e paliativas para tentar manter a conexão com seus estudantes que não tinham acesso à internet e a equipamentos digitais adequados. Se a pandemia de coronavírus em 2020 foi um evento dramático para todo o setor educacional no país, trata-se, ainda assim, de questionar desigualdades e privilégios.

\section{DIREITO OU PRIVILÉGIO? DESIGUALDADES DIGITAIS E EDUCAÇÃO NA PANDEMIA} á muito se discute no Brasil o quanto a educação é, de fato, um direito. Anísio Teixei-

ra trouxe tal questionamento no fim dos anos 1950: "educação não é privilégio", afirmara o autor ao defender a educação como um direito, lutando pela universalização da escola pública gratuita e de qualidade no Brasil (Teixeira, 1995; Nunes, 2000)ํ. Nas duas últimas décadas do século XX, com a Constituição de 1988 e a Lei de Diretrizes e Bases da Educação de 1996, a educação no país passou a ser formalmente garantida como "direito de todos e dever do Estado e da família" (Brasil, 1988). No entanto, inúmeras pesquisas ano a ano constatam as enormes desigualdades educacionais que assolam o país tanto no ensino básico como no ensino superior (Silva e Hasenbalg, 2000; Castro, 2009; Artes e Ricoldi, 2015; Macedo, 2019a). Apesar de alguns avanços recentes na democratização das instituições educacionais, ainda temos um sistema de ensino desigualmente marcado por critérios de raça, classe e gênero entre estudantes, além das diferenças regionais brasileiras.

Se tais desafios não são novos, com a eclosão da pandemia de coronavírus em 2020 e o consequente fechamento das escolas, tais mecanismos de criação e reprodução de desigualdades se mostraram ainda mais atuantes. Diversos operadores de diferenciação social se acentuaram, aumentando as distâncias educacionais entre escolas públicas e privadas, ricos e pobres, "herdeiros" e "não herdeiros" (Bourdieu, 2015). Para além das desigualdades educacionais e sociais, somaram-se desigualdades digitais.

Vale ressaltar que as desigualdades digitais refletem ou espelham desigualdades sociais mais amplas, já constituindo desde o fim do século XX mais um lócus de estratificação social no Brasil. Conforme diferentes estudos indicam, as desigualdades digitais apresentam forte correlação com critérios de renda, além da articulação com marcadores sociais da diferença, como raça, gênero e idade (Ribeiro et al., 2013; Parreiras e Macedo, 2020a). Embora a internet tenha se disseminado no Brasil no fim dos anos 1990 entre as classes média e alta, foi apenas nos anos 2010 que se popularizou, especialmente por meio de smartphones (Parreiras, 2008; Miskolci e Baliero, 2018). Ainda assim, tais usos são marcados por intensas desigualdades. Dados da pesquisa TIC Domicílios de 2019 apontaram que 20 milhões de domicílios 
brasileiros não possuíam internet ( $28 \%$ da quantidade total). Ao fazermos a intersecção com classe, apareciam desigualdades muito expressivas: enquanto nas classes econômicas $A$ e $B$ a presença da internet beirava os 100\% em 2019, nas classes D e E, o acesso caia para $50 \%$. Em relação à posse de equipamentos, as desigualdades também eram grandes: enquanto nas classes A e B a posse de computador era um item frequente (95 e 85\%, respectivamente), nas classes D e E, a presença do computador caia para 14\% (Centro Regional de Estudos para 0 Desenvolvimento da Sociedade da Informação, 2019; Parreiras e Macedo, 2020a).

Além do acesso à internet e da posse de equipamentos digitais adequados, o chamado letramento digital também é desigual na sociedade brasileira, de modo que nem todos os usuários têm intimidade com as novas tecnologias para saber manejá-las corretamente (Rezende, 2016)2. Os usos são muito diversos e relacionam-se com diferenças ligadas à escolaridade, ao capital cultural $^{3}$, à idade, ao tipo de inserção profissional, entre outras variáveis. As reflexões do historiador Carlos Ginzburg sobre a internet, já mencionadas anteriormente, também destacam essa questão do chamado letramento ou domínio digital:

Para levar a cabo uma pesquisa navegando na web, nós precisamos saber como dominar os instrumentos do conhecimento: em outras palavras, nós precisamos dispor de um privilégio cultural que, como posso dizer com base na minha própria experiência pessoal, é como uma regra ligada ao privilégio social (Ginzburg, 2016, s/p).

Ginzburg debate a questão dos privilégios culturais e sociais em relação ao domínio dos instrumentos de uso da internet. No entanto, tendo a educação como foco, cabe cada vez mais questionar a conectividade enquanto um privilégio social, quando já poderia ser compreendida como um direito. Esse é, aliás, o entendimento da Organização das Nações Unidos (ONU), que já reconheceu o acesso à internet como um direito humano universal (Bacciotti, 2014).

Nesse debate, uma breve comparação internacional pode ser interessante. Destaca-se o caso do Uruguai, que, desde 2007, por meio de uma política educacional intitulada Plan Conectividad Educativa de Informática Básica para el Aprendizaje en Línea (CEIBAL), distribui um computador por estudante da rede pública de todo o país. Além da formação de professores para uso de tecnologias digitais, tal política também preparou e instalou internet em todas as escolas públicas, mediante acordo com a companhia estatal de comunicações (Moreira, Lima e Brito, 2019). Ainda que se leve em consideração as diferenças geográficas e populacionais dos dois países, o caso uruguaio aponta tendências importantes no combate a essa forma de desigualdade.

No Brasil, embora diferentes políticas educacionais, como o Plano Nacional de Educação 2014-2024, prevejam a ampliação da conectividade e do uso de tecnologias digitais no 
processo educacional (Moreira, Lima e Brito, 2019), pesquisas indicam grandes desigualdades. Dados da pesquisa Tecnologia de Informação e Comunicação (TIC) Educação, cujo objetivo é compreender o acesso, o uso e a apropriação das TICs em escolas privadas e públicas brasileiras, são reveladores desse cenário. Nesse levantamento, apenas 14\% das escolas públicas declararam utilizar alguma plataforma ou ambiente virtual de aprendizagem em 2019, número que chega a $64 \%$ nas escolas particulares, apontando para diferença muito expressiva entre as redes pública e privada. Outro dado relevante é que $58 \%$ dos alunos declararam utilizar o celular para atividades escolares, destes, $18 \%$ só possuíam acesso à internet pelo telefone. Em relação aos professores, apenas 33\% disseram ter tido algum tipo de formação para uso do computador e da internet para atividades escolares (Centro Regional de Estudos para o Desenvolvimento da Sociedade da Informação, 2020; Parreiras e Macedo, 2020b).

Se tais desigualdades já eram conhecidas no Brasil, durante a pandemia, com a transferência do ensino presencial para o ensino remoto emergencial, a diferença de acesso ampliou tais diferenças. Dados da Rede de Pesquisa Solidária ${ }^{4}$ de agosto de 2020 mostram que, entre março e julho de 2020, mais de 8 milhões de crianças de 6 a 14 anos não fizeram quaisquer atividades escolares em casa. No mês de julho, enquanto apenas $4 \%$ das crianças mais ricas ficaram sem qualquer atividade escolar, tal número saltou para 30\% entre as crianças mais pobres. 0 relatório conclui: "Com a omissão do Estado no acompanhamento das famílias mais pobres, a diferença de atividades realizadas em casa, entre pobres e ricos, pode chegar a 224 horas, o equivalente a 50 dias letivos" (Rede de Pesquisa Solidária, 2020: 1). Na rede estadual de educação de São Paulo, mesmo com a criação de um aplicativo para transmissão de aulas online que não consome o pacote de internet do usuário ${ }^{5}$ apenas $27,3 \%$ dos estudantes acompanhavam as atividades quando mensurada a presença em alguns dias de maio e junho de $2020^{6}$. No estado de São Paulo, perto do fechamento do ano, cerca de 500 mil estudantes não entregaram qualquer atividade ${ }^{7}$. Mais uma vez, a falta de conectividade foi uma das principais causas dessa perda de conexão com a escola, penalizando ainda mais os estudantes de menor renda.

Se no estado de São Paulo foram formuladas algumas iniciativas no setor educacional, ainda que insuficientes, no âmbito federal o completo descaso e omissão foi o que prevaleceu mais uma vez (Macedo, 2019b). Enquanto os números de mortos pela COVID-19 não paravam de subir, o governo federal liderado por Jair Bolsonaro desdenhou da população e minimizou a crise, atacando o povo brasileiro por diferentes frentes. Na educação, não foi diferente. 0 Ministério da Educação (MEC), em gestão atribulada que resultou na demissão de um ministro em plena pandemia, recusava-se a adiar a maior prova brasileira de ingresso nas universidades, o Exame Nacional do Ensino Médio (ENEM), afirmando no início de maio que 
o sistema educacional "não foi feito para corrigir injustiças". Ao contrário, o então ministro criou uma campanha nas mídias que afirmava que, mesmo ante a pandemia, "a vida não pode parar", orientando todos os estudantes a estudarem pela internet: "é preciso ir à luta e se reinventar", afirmava a campanha de manutenção da prova ${ }^{8}$. Após grande pressão popular via redes sociais, a data da prova foi redefinida (Parreiras e Macedo, 2020b). Já em setembro de 2020, o novo ministro da Educação, o pastor Milton Ribeiro, disse em entrevista a um dos principais jornais do país que as questões da volta às aulas e do acesso à internet para estudos não eram atribuições de seu ministério ${ }^{9}$. Novamente, percebia-se que a estratégia do governo federal era fazer o mínimo possível para não ter responsabilidade sobre a crise. Ao findar 0 ano de 2020, apesar de alguns projetos de lei formulados no Legislativo ${ }^{10}$, nenhuma política pública federal de garantia à conectividade e à educação remota para estudantes do ensino público tinha sido aprovada no país.

Mais do que nunca, durante a pandemia do coronavírus em 2020, a educação no Brasil tornou-se um privilégio, deixando milhares de estudantes sem garantia de seu direito à educação. Nesse quadro de crise, coube a agentes diversos com familiares, professores e diretores de escolas públicas encontrarem soluções criativas e paliativas para tentar manter a conexão com os seus estudantes que não tinham acesso a equipamentos digitais adequados ou à internet, caso da EA-FEUSP, em São Paulo, conforme relato a seguir.

\section{DESAFIOS DA ESCOLA DE APLICAÇÃO DA FEUSP EM MEIO À PANDEMIA}

esta parte do artigo, focaliza-se o caso específico da EA-FEUSP em meio à transferên-
cia para o ensino remoto durante a pandemia do coronavírus em 2020. 0 relato aqui apresentado é parte de pesquisa coletiva que integro, realizada na FEUSP, que tem como foco memória, história e diversidade na escola, integrando o projeto temático Saberes e práticas em fronteiras: por uma história transnacional da educação (1810-...) (Processo Fapesp n 2018/26699-4). Além de ser pesquisadora de pós-doutorado, também tenho um filho matriculado nessa escola e integro a gestão atual da Associação de Pais e Mestres (APM), fazendo parte da comunidade escolar.

Vale contextualizar brevemente a EA, que está localizada dentro da Cidade Universitária, no bairro Butantã, na cidade de São Paulo (SP). Ligada à FEUSP, em 2019 a escola possuía 715 alunos entre ensinos fundamental e médio, 51 professores (sendo 12 com contratos temporários de 12 horas) e 21 funcionários (Escola de Aplicação, 2020a). Anualmente, 0 ingresso na escola se dá por meio de sorteio realizado para 60 crianças do $1^{\circ}$ ano de ensino fundamental, sendo um terço das vagas para filhos de servidores da FEUSP, um terço para 
filhos de servidores de outras unidades da universidade e um terço das vagas destinado para ampla concorrência ${ }^{11}$, atendendo, assim, a perfis sociais e econômicos diversos ${ }^{12}$. Para os demais anos, também são sorteadas vagas remanescentes.

A história oficial da EA inicia-se em 1959, tendo comemorado 60 anos em 2019. Sua origem é parte do contexto de formação do Centro Brasileiro de Pesquisas Educacionais (CBPE), criado sob a coordenação de Anísio Teixeira em 1955. Como parte desse projeto, foi criado em 1956 o Centro Regional de Pesquisas de São Paulo (CRPE-SP), tendo Fernando Azevedo como diretor geral (Ferreira, 2001), e, em 1959, deu-se a criação de uma primeira classe de $1^{\circ}$ ano primário da escola experimental, dando origem à escola. Em 1962, seu nome foi alterado para Escola de Demonstração e, em 1972, após a extinção do CRPE, a escola vinculou-se à FEUSP, passando a se chamar Escola de Aplicação (Gordo, 2010). Desde seu primeiro regimento, a escola teve como um de seus objetivos "servir de campo de observação" a professores e estagiários da universidade (Gordo, 2010: 23), compromisso que se mantém até a atualidade (Escola de Aplicação, 2020a).

Em relação às orientações pedagógicas, além do conteúdo regular, o ensino na escola tem sido caracterizado pela aposta conjunta em projetos, atividades extracurriculares e estudos do meio. Professores qualificados e dedicados exclusivamente à escola contribuíram para a consolidação de um ensino de qualidade. No entanto, desde 2015, com o Programa de Incentivo à Demissão Voluntária (PIDV) implementado pela USP para reduzir custos com folha de pagamento, a escola vem encontrando dificuldades para manter seu projeto educativo, reduzindo ainda mais o quadro de funcionários e substituindo professores efetivos com contratos de 40 horas semanais por professores temporários com contratos de apenas 12 horas e salários bastante reduzidos (Escola de Aplicação, 2020a). Conforme a história dessa escola revela, se as sucessivas crises fazem parte da trajetória da instituição (Azanha, 1987, 1999; Gordo, 2010) $)^{13}$, no período recente os desafios não têm sido menores.

Conforme definido no Plano Escolar de 2020, trata-se de uma escola "comprometida com os direitos humanos, a igualdade de direitos, o reconhecimento e a valorização das diferenças e das diversidades, a democracia e a formação para a cidadania" (Escola de Aplicação, 2020a: 34). Entre outras marcas da escola, também está sua gestão democrática (Silva, Gallego e Vicentini, 2017). Torna-se, assim, necessário enfatizar o quanto o ensino presencial, baseado em experiências variadas de aprendizagem, socialização, debates críticos e consciência corporal, tornaram o ensino remoto emergencial implementado em 2020 uma alternativa apenas paliativa, que muito se distancia do cotidiano escolar tido como desejável nessa instituição.

Vale também destacar que, diferentemente de outras escolas estaduais de São Paulo, a EA foi desvinculada do sistema estadual de ensino, tendo sua gestão integralmente trans- 
ferida para a universidade. Assim, ante a pandemia, as saídas oferecidas pela Secretaria da Educação do Estado de SP em 2020 — como a transmissão de aulas online por meio de um aplicativo que não consome o pacote de dados de internet do usuário ou por meio de um canal de televisão - não constituíram alternativa viável para a EA. Na falta de saídas oficiais para enfrentar o desafio da educação em meio à pandemia, coube à equipe pedagógica da escola, em parceria com a comunidade escolar, buscar soluções para tentar oferecer um ensino remoto democrático e inclusivo, marca da escola.

Assim, em março de 2020, dadas as orientações federais e estaduais ${ }^{14}$ que passaram a incentivar a continuidade do ano letivo por meio da transferência do ensino presencial para o ensino remoto emergencial, a equipe pedagógica da EA — assim como diversas instituições de ensino - enfrentou uma grande crise ante a possibilidade de seguir com o ano letivo em condições tão adversas. Conforme descrito em balanço oficial apresentado pela escola ao fim do primeiro semestre de 2020, tratava-se de um impacto sem precedentes no processo escolar: "A experiência de vivenciar um tempo de isolamento social não tem registro na história da Escola de Aplicação da FEUSP, em seus sessenta anos de existência" (Escola de Aplicação, 2020b: 1). Tal condição atingia um dos princípios fundamentais do projeto político pedagógico da escola, que "prevê a interação entre sujeitos como um dos pilares das ações educativas e pedagógicas e, por extensão, como elemento fundamental na promoção da aprendizagem" (Escola de Aplicação, 2020b: 1). Faria sentindo seguir o ensino das diferentes disciplinas com os portões da escola fechados?

Ante esse cenário de incertezas, e da continuidade da pandemia, direção e professores optaram por realizar uma transição gradual, que pode ser sintetizada em três fases. Na primeira fase, disponibilizaram-se conteúdos semanais no site da escola, organizados por ciclo escolar e ano, para serem acessados de forma assíncrona, conforme a disponibilidade dos estudantes. Na segunda fase, além das atividades domiciliares disponibilizadas no site, passaram a ocorrer encontros online semanais entre estudantes e professores, especialmente voltados em garantir a troca de sentimentos e experiências durante a pandemia. Na terceira fase, dada a persistência da doença, passaram a ocorrer também aulas online com diferentes periodicidades para ensino fundamental I, ensino fundamental II e ensino médio, metodologia utilizada até o encerramento do ano, em dezembro de 2020, combinando as chamadas atividades síncronas e assíncronas (Escola de Aplicação, 2020c). Progressivamente, além das atividades postadas no site da escola e das aulas online realizadas via plataforma Google Meet, novas ferramentas foram incorporadas pelos professores. No ensino fundamental I, conforme desenvolvo adiante, ferramentas como jogos online para realização de operações matemáticas, blog com atividades de artes e educação física, vídeos no YouTube com assuntos 
ligados aos conteúdos ministrados, entre outros recursos, foram sendo descobertos e incorporados à rotina educacional. Ainda assim, com acessos bastante desiguais entre os diferentes estudantes da escola.

Entre as muitas preocupações trazidas pela crise, um ponto central eram as desigualdades digitais. Desde o fechamento dos portões da escola em março, diferentes setores manifestaram preocupação com os muitos estudantes que não estavam conseguindo acompanhar as atividades remotas por não terem acesso, seja à rede de internet no domicílio, seja aos equipamentos eletrônicos adequados para o estudo. No mês de abril, a equipe escolar realizou uma primeira pesquisa sobre acesso digital, constatando que 58 alunos (de um total de 715) não tinham acesso à internet e/ou a equipamentos adequados, impossibilitando seu acompanhamento do ano letivo a distância ${ }^{15}$. Embora, proporcionalmente, o número de estudantes sem conectividade não fosse tão alto (menos de 10\%, muito diferente de outras escolas públicas do estado de São Paulo), ainda assim resultava muito desafiador. Como pode uma escola pública ministrar aulas inacessíveis justamente para seus estudantes de menor renda? Faz sentido formular conteúdo para alguns, deixando outros tantos para trás? Foram algumas das perguntas manifestas por professores e gestores da instituição em reuniões online ocorridas no fim do primeiro semestre. Nesse primeiro momento, conforme registrado em documento escolar do fim do primeiro semestre, a orientação seria estudar uma logística para enviar atividades por Correios para aqueles estudantes que se encontravam sem acesso (Escola de Aplicação, 2020b).

Tal constatação gerou uma maior mobilização entre diversos setores da escola: professores e funcionários, diretoras, APM e comunidade escolar como um todo. "Nenhum estudante deve ficar para trás" foi a resposta de uma dirigente da instituição ante a pressão de algumas famílias que pediam conteúdos online mais frequentes. Tensões e dúvidas fizeram parte do processo, manifestas especialmente nos grupos online de trocas de mensagem que reuniam familiares dos estudantes, dos quais também faço parte. De um lado, algumas mães, pais e familiares aflitos reivindicando mais aulas online e um ensino a distância mais bem estruturado, visando a não prejudicar ainda mais o ano letivo de suas crianças e jovens; de outro lado, o silêncio de estudantes e familiares sem conectividade em meio à crise, alheios às aulas, lições e discussões.

Nesse contexto de dúvidas e desafios que foi criada a "Campanha EA Conectada". Realizada em parceria entre equipe pedagógica, diretoria, APM e familiares de estudantes, a campanha teve como objetivo tentar garantir a conectividade de todos os estudantes da escola por meio da arrecadação de equipamentos eletrônicos e obtenção de kits de internet móvel ${ }^{16}$. Em paralelo, no mês de maio, tornou-se de conhecimento da comunidade escolar 
que a administração da USP realizou algumas ações de inclusão digital, distribuindo cerca de dois mil kits de internet para os universitários de baixa renda, conforme noticiado no Jornal da USP17. No entanto, nada foi direcionado para o ensino básico. A diretoria da EA solicitou então à universidade 0 atendimento dos alunos que se encontravam sem acesso. Após uma primeira negativa, um dos setores ligados à universidade, de maneira autônoma e pedindo sigilo na doação, atendeu ao pedido, doando modems com habilitação para 20 gigas mensais, concedidos inicialmente por seis meses. Por meio dessas ações diversas, os resultados da campanha podem ser considerados satisfatórios, conseguindo um total de 56 equipamentos eletrônicos ao longo de $2020^{18}$. Vale destacar, contudo, que tais conquistas foram obtidas por meio de lutas e estratégias diárias de enfrentamento da crise, não havendo nenhuma resposta coordenada da reitoria da universidade em relação aos seus estudantes crianças e adolescentes em idade escolar.

0 passo seguinte foi identificar, com maior precisão do que a obtida na primeira listagem, quem eram os estudantes que deveriam ser considerados prioridade na distribuição dos equipamentos. Se, à primeira vista, tal processo parecia simples, à medida que se iniciou revelou-se cada vez mais desafiador: como, durante a pandemia, contatar justamente aqueles estudantes e familiares que estavam sem conexão digital? Se é obrigatório o cadastro anual de uma conta de e-mail na secretaria da escola, muitas famílias perdem a senha e, assim, 0 acesso ao e-mail, tendo dificuldades também na solicitação de nova senha, questões ligadas ao domínio ou ao letramento digital, conforme discutido na primeira parte deste texto. 0 contato por aplicativos de mensagens (WhatsApp), mais acessível no Brasil justamente porque usado pelos celulares e disponível no pacote de dados de praticamente todos os planos de internet móvel, foi uma alternativa fundamental para acessar diversas famílias. Em alguns casos, só houve contato com as famílias após tentativas com outros parentes, localizados também por meio do contato celular pelo aplicativo de troca de mensagens.

A partir de agosto de 2020, foram marcados três plantões de entregas de equipamentos no espaço físico da escola, aberto exclusivamente para esse fim. Por terem uma navegabilidade mais acessível, para estudantes do ensino fundamental I e primeiros anos do ensino fundamental II, foram entregues tablets novos com os modems de internet. No dia da entrega, as equipes da escola e da APM (da qual fiz parte) envolvidas na ação realizaram o trabalho de entrega em várias etapas. Cumprindo os protocolos de biossegurança exigidos durante a pandemia, como 0 uso de máscara e disponibilização de álcool em gel, marcaram-se horários por família a fim de comunicar em detalhes as regras e a usabilidade dos equipamentos.

Nesse período, outro ponto desafiador foi constatar que muitos estudantes que estavam ausentes das aulas online, na verdade, possuíam equipamentos digitais e internet em 
casa. Tais dificuldades apontam para os limites da educação remota, que pressupõe, além da posse dos materiais necessários, a organização de um espaço adequado para estudos dentro de casa e o acompanhamento de familiares que, por diferentes motivações (sociais, econômicas, de saúde ou pela rotina de trabalho), não estava sendo possível de ocorrer em algumas famílias.

Conforme já destacava Bernard Lahire (2004: 26) em pesquisa nos anos 1990 com estudantes de ensino fundamental na França, a organização da casa do aluno não constitui um elemento sem importância na transmissão do capital escolar: "a regularidade das atividades, dos horários, as regras de vida estritas e recorrentes, os ordenamentos, as disposições ou classificações domésticas produzem estruturas cognitivas ordenadas, capazes de pôr ordem, gerir, organizar os pensamentos". Assim, "se a ordem moral e material em casa pode ter uma importância na escolaridade dos filhos" (Lahire, 2004: 26), durante a pandemia, na ausência de outros espaços educativos que não a casa da família, tais condicionantes mais do nunca se mostraram relevantes no processo educacional.

Esse foi, por exemplo, o caso de uma família atendida durante os plantões da campanha: embora tivessem internet em casa, a mãe trabalhava como enfermeira em um hospital, estando, portanto, ausente de casa durante a semana para trabalhar; seu único filho, estudante do ensino fundamental, tinha que ir para a casa da avó, idosa acamada que vivia sozinha, que era ao mesmo tempo cuidadora e cuidada pelo jovem. Como garantir uma rotina adequada de estudos e estímulo à educação em tais condições? Nesse caso, a doação de um equipamento digital novo foi apenas um paliativo, ante rotinas tão brutalmente transformadas pela pandemia e pelo fechamento das escolas.

De todo modo, o resultado desse esforço de inclusão digital realizado pela escola se revelou positivo, tendo atendido um total de 53 estudantes em 2020 (Escola de Aplicação, 2020c). Esse também foi o caso de Pedro ${ }^{19}$, estudante de ensino fundamental I que ficou meses sem acesso às atividades online. Residindo apenas com o pai, que se encontrava em situação financeira bastante instável desde antes da pandemia, após o recebimento de tablet e kit de internet pela campanha, Pedro conseguiu participar das aulas online, momento marcado por grande emoção quando reviu a professora e os colegas depois de meses sem contato. Ainda assim, seguiu atrasando lições e faltando em algumas aulas online, especialmente nas semanas que tinha que acompanhar seu pai em trabalhos temporários no setor de construção civil.

Assim como para Pedro, o envolvimento entre crianças do ensino fundamental I e escola durante esse período foi marcado por avanços ao longo do ano, mas também por muitos desafios. Para essa fase de ensino, a partir do segundo semestre de 2020, além de aulas síncronas 
online realizadas via Google Meet (de uma a quatro aulas de uma hora cada por semana, dependendo do ano escolar), foram mantidas atividades domiciliares assíncronas disponibilizadas no site, que as crianças podiam responder no caderno ou em folha impressa. 0 estudante Pedro, por exemplo, contou com o auxílio de outra mãe da comunidade escolar que possuía impressora e toda semana disponibilizava as folhas de atividade para ele. Tais atividades foram organizadas por conteúdos disciplinares como português, matemática e ciências. Vídeos do YouTube e jogos online de matemática, entre outros recursos disponíveis online, eram indicados para acompanhar essas lições. As atividades já realizadas pelos estudantes eram fotografadas e semanalmente devolvidas às professoras por e-mail ou por aplicativo de troca de mensagens WhatsApp, metodologia considerada fácil por algumas famílias e muito desafiadora para aquelas com menor facilidade nas tecnologias digitais. As atividades de artes e educação física foram disponibilizadas num blog, de maneira assíncrona, que recomendava semanalmente diferentes atividades de desenho, pintura, música e exercícios corporais com base em um mesmo tema do cotidiano, como "janelas", "espelhos", "quarto" ou "cozinha". Esse conjunto de atividades foi organizado para cumprir a carga horária estipulada de 800 horas anuais, conforme Parecer 15/2000 do MEC de agosto de $2020^{20}$ (Escola de Aplicação, 2020c).

Mais uma vez, a questão das desigualdades digitais, compreendida aqui como fenômeno que opera em várias camadas, teve impacto no aproveitamento diferencial dessas atividades, ferramentas e conteúdos. Para além da questão do acesso à internet, da adequação dos equipamentos digitais e da facilidade de manejar essas tecnologias, a disponibilidade de tempo, saúde e interesse dos familiares para acompanhar tais atividades constituiu elemento central para um bom aproveitamento, revelando-se muito desigual. A pandemia impactou as famílias da escola de muitas maneiras, gerando instabilidades econômicas, psicológicas, sociais e de saúde. Registraram-se, inclusive, famílias que perderam suas casas por não conseguir manter o aluguel ante o desemprego repentino de todos os membros da casa. Sem contar os tantos outros desafios ligados ao ensino remoto emergencial, como a dificuldade de controle dos familiares para que os alunos entrem nas aulas no horário correto, dificuldade de controlar o tempo de tela de crianças e adolescentes que, mais do que nunca, passaram muitas horas diárias entretidos com jogos e vídeos no YouTube, dificuldade de cumprir os prazos das lições e dúvidas com o conteúdo ministrado. A manutenção do interesse dos estudantes em relação aos estudos, bem como a solidão e as saudades dos colegas, também surgiu como obstáculo para o andamento da educação formal durante a pandemia.

Nesse quadro, o processo de avaliação de ensino e aprendizagem também foi impactado. Se uma das marcas da EA-FEUSP era a avaliação formativa, que se empenha em 
acompanhar o processo de aprendizagem de seus estudantes ao longo do ano, tal metodologia, mais uma vez, viu-se profundamente impactada com o ensino remoto. Nos conselhos de classe, professoras e professores expressaram incômodo pela mudança de paradigma, impulsionando a busca de alternativas viáveis e flexíveis para a avaliação em tempos de pandemia (Escola de Aplicação, 2020c).

Em síntese, se nesse período de crise e incertezas, algumas conquistas foram obtidas, muitos desafios permaneceram. Embora tentar garantir a conexão digital de todos os estudantes tenha se revelado um passo fundamental na busca de um ensino remoto democrático, constatou-se que apenas o acesso aos equipamentos e à internet não bastava para garantir a participação de todos os alunos nas atividades remotas. Assim, a experiência da EA-FEUSP em 2020 mostrou que garantir a conectividade foi uma etapa indispensável, mas não a única necessária para garantir o direito à educação em tempos de crise.

\section{CONSIDERAÇÕES FINAIS}

Conforme reflexão de Roger Chartier, se a revolução eletrônica, em contraponto à revolução de Gutenberg no século XV, representou uma "revolução nas estruturas do suporte material do escrito, assim como nas maneiras de ler" (Chartier, 1999: 13), tratou-se aqui de refletir sobre uma mudança abrupta nos suportes materiais da educação formal em 2020, que, por conta da pandemia, teve que ser substituída às pressas para o ambiente online por meio de aparatos tecnológicos, esvaziando repentinamente salas de aulas, quadras, bibliotecas e parquinhos por muitos meses. No seu lugar, lições e aulas online apenas para quem tinha acesso aos equipamentos digitais e à internet.

Neste artigo, discutiram-se impactos na educação durante a pandemia de COVID-19, focalizando a questão do acesso às atividades online por estudantes do ensino básico. Especialmente, debateu-se a questão das desigualdades digitais e sua relação com a educação. Contra a expectativa espraiada em meados dos anos 2000 de que a internet seria um grande espaço de democratização do conhecimento e das relações sociais (Miskolci e Baliero, 2018), diversos estudos recentes apontaram na direção contrária, indicando a somatória de privilégios e de reforço de desigualdades sociais, educacionais e digitais. Ante esse quadro, agravado ainda mais pela pandemia de coronavírus que fechou escolas durante quase todo o ano de 2020, o artigo debateu a necessidade de democratização do acesso à internet, imprescindível para manter a conexão entre escolas públicas e estudantes nesses tempos de crise. Retomando as palavras de Ginzburg (2016, s/p) apresentadas no início deste artigo, trata-se de fazer da internet, de fato, um "instrumento democrático". 
Ainda assim, é preciso reconhecer que garantir a conectividade para viabilizar o ensino online é apenas um paliativo em período de crise, já que o processo de aprendizagem não é só transmissão de conteúdo, mas envolve diversas outras dimensões, entre as quais a sociabilidade presencial entre crianças e adolescentes é fundamental. 0 acesso online aos conteúdos educacionais, apesar de indispensável, não basta para garantir uma educação de qualidade.

Se a crise causada pela pandemia de coronavírus foi um evento dramático para todo o setor educacional, mais uma vez, retomando as palavras de Anísio Teixeira, não podemos aceitar "o dualismo pacífico entre os 'favorecidos' ou 'privilegiados' e os desfavorecidos ou desprivilegiados" (Teixeira, 1956b: 18). Trata-se, ao contrário, de lutar pela "educação comum", de fato acessível a todos, mesmo em tempos de crise.

Conflitos de interesse: Não há conflito de interesses.

Fonte de financiamento: FAPESP (Processo N 19/25903-0)

\section{NOTAS}

1 Disse Anísio Teixeira (1956a: 4) em conferência proferida em 1956: "[...] estou seguro de que não estamos aqui para discutir, como é tanto do nosso gosto, a educação dos poucos, a educação dos privilegiados, mas a educação dos muitos, a educação de todos, a fim de que se abra para o nosso povo aquela igualdade inicial de oportunidades, condição mesma para a sua indispensável integração social".

2 Conforme destaca Rezende (2016: 101) citando outras pesquisas na área: " [... o letramento digital não é somente uma questão funcional de manusear o computador e fazer pesquisas; é necessário saber localizar e selecionar os materiais por meio de navegadores, hyperlinks e mecanismos de procura, entre outros".

3 Capital cultural é um conceito cunhado por Pierre Bourdieu (2015) que se refere aos níveis diferenciais de escolaridade, posse de diplomas escolares e acesso a bens culturais.

4 Criada na pandemia de COVID-19, a Rede de Pesquisa Solidária reuniu cerca de 50 pesquisadores de áreas diversas para trazer dados confiáveis durante a crise. A pesquisa sobre educação durante a pandemia, divulgada no boletim $n^{\circ} 22$, foi coordenada pelos pesquisadores do Centro Brasileiro de Análise e Planejamento (CEBRAP) Ian Prates e Hellen Guicheney e utilizou dados da Pesquisa Nacional por Amostra de Domicílios (PNAD) COVID19 de julho de 2020, entre outras fontes (Rede de Pesquisa Solidária, 2020). 
5 A Secretaria de Educação do Estado de São Paulo passou a utilizar uma plataforma própria de produção de conteúdo educacional remoto por meio do Centro de Mídias de São Paulo. As aulas podiam ser acessadas por aplicativos que não gastavam o pacote de dados $4 \mathrm{G}$ do usuário, por redes sociais como Facebook ou por meio de um canal de televisão. Disponível em: https://www.educacao.sp.gov.br/noticias/aplicativos-promovem-inclusao-digital-na-rede-estadual-de-ensino-de-sao-paulo/. Acesso em: 07 set. 2020.

6 Dados do Sindicato dos Professores do Ensino Oficial do Estado de São Paulo (APEOESP). Disponível em: http://www.apeoesp.org.br/noticias/noticias-2020/levantamento-da-apeoesp-mostra-que-ensino-a-distancia-tem-participacao-media-de-27-3-dos-alunos/. Acesso em: 16 set. 2020.

7 Informações veiculadas em reportagem do jornal Folha de S. Paulo de 11 de novembro de 2020. Disponível em: https://www1.folha.uol.com.br/educacao/2020/11/em-sp-500-mil-alunos-nao-fizeram-nenhuma-atividade-letiva-durante-a-pandemia.shtml\#: :text=Mais\%20 de $\% 20500 \% 20$ mil\%20alunos, de \%20estudantes \%20das\%20escolas\%20paulistas.\&tex$\mathrm{t}=$ Em $\% 20$ entrevista \%20\%C3\%A0\%20Folha\%2C\%200,pelo\%20desempenho\%20escolar\%20neste\%20ano. Acesso em: 15 dez. 2020.

8 Informações que podem ser conferidas em reportagem do jornal 0 Globo de 04 de maio de 2020. Disponível em: https://oglobo.globo.com/sociedade/coronavirus/estudantes-criticam-video-do-inep-sobre-enem-que-diz-que-vida-nao-pode-parar-24410158. Acesso em: 18 dez. 2020.

9 Entrevista concedida ao jornal Estadão em 24 de setembro de 2020. Disponível em: https:// educacao.estadao.com.br/noticias/geral,voltas-as-aulas-no-pais-e-acesso-a-web-nao-sao-temas-do-mec-diz-ministro,70003450120. Acesso em: 18 dez. 2020.

10 Entre as propostas formuladas no Legislativo, destaca-se a proposta da deputada Tabata Amaral, aprovada na Câmara dos Deputados em 18 de novembro de 2020, a qual deve ser votada no Senado no início de 2021. Informações disponíveis em: https://g1.globo.com/ politica/noticia/2020/12/18/camara-aprova-texto-para-garantir-internet-gratis-a-professores-e-alunos-da-rede-publica.ghtml. Acesso em: 23 dez. 2020.

11 Sorteios esses que são bastante concorridos, reunindo anualmente cerca de mil famílias inscritas (Escola de Aplicação, 2020a).

12 Segundo o Plano Escolar de 2020, o perfil socioeconômico das famílias atendidas pela escola é bem heterogêneo. Como a escola não possui merenda, entre outros apoios, os estudantes de baixa renda recebem auxílio financeiro da Superintendência de Assistência Social da Universidade (SAS) (Escola de Aplicação, 2020a). Em 2017, 91 estudantes receberam o auxílio. 
13 Conforme a tese de Nívia Gordo (2010) revela, entre outas crises, os anos 1980 foi um período marcado por um amplo debate a respeito da pertinência ou não de uma Escola de Aplicação na Universidade de São Paulo. Após posições diversas entre reitoria e professores da Faculdade de Educação, em 1985, decidiu-se pela manutenção e ampliação da escola, implementado o segundo grau conforme projeto de José Pires Azanha (Azanha, 1987; Gordo, 2010).

14 No início de abril de 2020, o governo federal assinou medida provisória que desobrigava as escolas de cumprirem os dias letivos, mas mantinha a obrigatoriedade de carga horária mínima. Em junho de 2020, o MEC passou a considerar as atividades remotas como parte da carga horária anual. Ver: https://g1.globo.com/educacao/noticia/2020/06/02/mec-autoriza-que-atividades-remotas-passem-a-valer-como-carga-horaria.ghtml. Acesso em: 02 set. 2020.

15 Destes 58 estudantes identificados na primeira listagem como estando sem acesso aos conteúdos digitais, 24 eram estudantes do ensino fundamental I, 24 do ensino fundamental Il e 10 do ensino médio.

16 A campanha atuou em três frentes: pedido de equipamentos digitais novos e usados para a comunidade por meio de divulgação em diferentes redes sociais, organização de vaquinha online com depósito direto na conta da APM e pedido realizado por e-mail para algumas grandes empresas de tecnologia.

17 Informações disponíveis em reportagem do Jornal da USP de 12 de maio de 2020: https:// jornal.usp.br/institucional/usp-distribui-mais-de-2-mil-kits-internet-para-estudantes-com-necessidades-socioeconomicas/. Acesso em: 02 set. 2020.

18 Na referida campanha, até dezembro de 2020, foram arrecadados 15 equipamentos eletrônicos usados, dinheiro para a compra de 16 tablets novos de marca nacional (por meio de vaquinha que contou com expressiva doação de ex-alunos da escola), doação, por meio da Faculdade de Ciências Farmacêuticas da USP, de 5 tablets aprendidos pela polícia federal e doação de 20 desktops novos por parte de uma grande empresa de tecnologia.

19 Nome fictício para garantir o sigilo do estudante.

20 De acordo com o Parecer 15/2020 do MEC, divulgado em agosto de 2020, em função de situação de "calamidade pública" ocasionada pela pandemia, os dias letivos foram flexibilizados, mas se manteve o compromisso de 800 horas anuais de carga horária escolar. Informações disponiveis em: http://portal.mec.gov.br/index.php?option=com_docman\&view=download\&alias=160391-pcp015-20\&category_slug=outubro-2020-pdf\&ltemid=30192. Acesso em: 02 fev. 2021. 


\section{REFERÊNCIAS BIBLIOGRÁFICAS}

ARTES, A.; RICOLDI, A. Acesso de negros no ensino superior: o que mudou entre 2000 e 2010. Cadernos de Pesquisa, v. 45, n. 158, p. 858-881, 2015. https://doi.org/10.1590/198053143273

AZANHA, J. M. P. A propósito de um debate sobre a Escola de Aplicação da FEUSP. 1987. Disponível em: <http:// www3.fe.usp.br/secoes/inst/novo/acervo_jmpa/PDF_SWF/128.pdf>. Acesso em: 23 dez. 2020.

AZANHA, J. M. P. O significado de uma Escola de Aplicação para a FEUSP. 1999 [1984]. Disponível em: <http:/l www3.fe.usp.br/secoes/inst/novo/acervo_jmpa/PDF_SWF/122.pdf>. Acesso em: 23 dez. 2020.

BACCIOTTI, K. Direitos humanos e novas tecnologias da Informação e Comunicação: o acesso à internet como direito humano. 2014. 186f. Dissertação (Mestrado em Direito) - Pontifícia Universidade Católica de São Paulo, São Paulo, 2014.

BOURDIEU, P. Escritos de Educação. Rio de Janeiro: Vozes, 2015.

BRASIL. Constituição da República Federativa do Brasil. 1988. Disponível em: <https://www.senado.leg.br/ atividade/const/constituicao-federal.asp>. Acesso em: 15 dez. 2020.

CHARTIER, R. A aventura do livro: do leitor ao navegador. São Paulo: Editora Unesp, 1999.

CENTRO REGIONAL DE ESTUDOS PARA O DESENVOLVIMENTO DA SOCIEDADE DA INFORMAÇÃO. Pesquisa TIC Domicilios 2019: principais resultados. 2019. Disponível em: <https://cetic.br/media/analises/tic_ domicilios_2019_coletiva_imprensa.pdf>. Acesso em: 16 set. 2020.

CENTRO REGIONAL DE ESTUDOS PARA O DESENVOLVIMENTO DA SOCIEDADE DA INFORMAÇÃO. Pesquisa T/C Educação. 2020. Disponível em: <https://www.cetic.br/pesquisa/educacao/. Acesso em: 23 dez. 2020.

CASTRO, J. Evolução e desigualdade na educação brasileira. Educação \& Sociedade, v. 30, n. 108, p.673-697, 2009. https://doi.org/10.1590/S0101-73302009000300003

ESCOLA DE APLICAÇÃO. Plano escolar 2020. Escola de Aplicação FEUSP. 2020a. Disponível em: <http:// www3.ea.fe.usp.br/wp-content/uploads/2020/05/Plano-Escolar-2020.pdf>. Acesso em: 02 set. 2020.

ESCOLA DE APLICAÇÃO. A Escola de Aplicação em tempos de pandemia e distanciamento social - junho de 2020. 2020b. Disponivel em: <http://www3.ea.fe.usp.br/ea-na-pandemia/>. Acesso em: 23 dez. 2020.

ESCOLA DE APLICAÇÃO. A Escola de Aplicação em tempos de pandemia e distanciamento social - novembro de 202". 2020c. Disponível em: <http://www3.ea.fe.usp.br/ea-na-pandemia/>. Acesso em: 23 dez. 2020.

FERREIRA, M. O Centro Regional de Pesquisas Educacionais de São Paulo (1956-1961). 2001. 194f. Dissertação (Mestrado) - Faculdade de Educação, Universidade de São Paulo, 2001. https://doi.org/10.11606/D.48.2001. tde-29102001-143059

GINZBURG, C. A internet é um instrumento potencialmente democrático. 2016. Disponível em: <https://www. fronteiras.com/artigos/carlo-ginzburg-a-internet-nao-apenas-remete-aos-livros-como-tambem-pressupoelivros-1427135419>. Acesso em: 07 set. 2020.

GORDO, N. História da Escola de Aplicação da FEUSP (1976-1986): a contribuição de José Mario Pires Azanha para a cultura escolar. 2010. 197f. Tese (Doutorado em Educação) - Faculdade de Educação, Universidade de São Paulo, São Paulo, 2010. https://doi.org/10.11606/T.48.2010.tde-11112010-110318 
LAHIRE, B. Sucesso escolar nos meios populares: as razões do improvável. São Paulo: Editora Ática, 2004.

MACEDO, R. M. Escolhas possíveis: narrativas de classe e gênero no ensino superior privado. Tese (doutorado em Antropologia Social). Universidade de São Paulo, São Paulo, 2019a.

MACEDO, R. M. Políticas educacionais e a questão do acesso ao ensino superior: notas sobre a deseducação. Cadernos de Campo (São Paulo-1991), v. 28, n. 2, p. 26-31, 2019 b.

MISKOLCI, R.; BALIEIRO, F. Sociologia digital: balanço provisório e desafios. Revista Brasileira de Sociologia, v. 6 , n. 12, p. 132-156, 2018. http://dx.doi.org/10.20336/rbs.237

MOREIRA, E.; LIMA, E.; BRITO, R. Estudo comparado das políticas públicas de inclusão digital: Brasil e Uruguai. Revista da Faculdade de Educação (Universidade do Estado de Mato Grosso), v. 32, n. 2, p. 1-22, 2019. https://doi.org/10.30681/2178-7476.2019.32.1741

NUNES, C. Anísio Teixeira entre nós: a defesa da educação como um direito de todos. Educação \& Sociedade, v. 21, n. 73, p. 9-40, dez. 2000. https://doi.org/10.1590/S0101-73302000000400002

PARREIRAS, C. Sexualidade no ponto.com: espaços e homossexualidades a partir de uma comunidade online. 2008. 209f. Dissertação (Mestrado em Antropologia Social) - Universidade Estadual de Campinas, Campinas, 2008.

PARREIRAS, C.; MACEDO, R M. Desigualdades digitais e educação: breves inquietações pandêmicas. In: TONIOL, R.; GROSSI, M. (orgs.). Cientistas sociais e o coronavírus. Florianópolis: Tribo da Ilha Editora, 2020a. p. 485-491.

PARREIRAS, C.; MACEDO, R M. Digital inequalities and education in Brazil during the COVID-19 pandemic: a brief reflection on the challenges of remote learning. Digital Culture \& Education, 2020b. Disponivel em: $<$ https://www.digitalcultureandeducation.com/reflections-on-covid19/digital-inequalities-and-education-inbrazil>. Acesso em: 16 set. 2020.

REDE DE PESQUISA SOLIDÁRIA. Nota Técnica $n^{\circ} 22$, de 28 de agosto de 2020. Disponível em: <https:// redepesquisasolidaria.org/wp-content/uploads/2020/09/boletimpps_22_28agosto.pdf>. Acesso em: 16 set. $/ 2020$.

REZENDE, M. 0 conceito de letramento digital e suas implicações pedagógicas. Texto livre: Linguagem e Tecnologia, v. 9, n. 1, p. 94-107, 2016. https://doi.org/10.17851/1983-3652.9.1.94-107

RIBEIRO, L. C. Q. et al. Desigualdades digitais: acesso e uso da internet, posiç̧ão socioeconômica e segmentação espacial nas metrópoles brasileiras. Análise Social, v. 207, n. XLVIII (2º), 288-320, 2013.

SILVA, N.; HASENBALG, C. Tendências da desigualdade educacional no Brasil. Dados, v. 43, n. 3, p. 423-445, 2000. https://doi.org/10.1590/S0011-52582000000300001

SILVA, V.; GALLEGO, R.; VICENTINI, P. Uma outra escola: a Escola de Aplicação da Faculdade de Educação da Universidade de São Paulo, seus alunos pequenos e a gestão democrática. Revista Galega de Educación Publicación de Nova Escola Galega, v. 67, p. 64-67, 2017.

TEIXEIRA, A. A escola pública, universal e gratuita. Revista Brasileira de Estudos Pedagógicos, v. 26, n. 64, 1956a, p. 3-22.

TEIXEIRA, A. Educaçãa não é privilégio. Revista Brasileira de Estudos Pedagógicos, n. 63, p. 3-31, 1956b.

TEIXEIRA, A. Educação não é privilégio. Rio de Janeiro: Ed. UFRJ, 1995. 